\title{
INTERSUBJETIVIDADE EM MICHEL HENRY: RELAÇÃO TERAPÊUTICA
}

\author{
Intersubjectivity in Michel Henry: The Therapeutic Relatinship \\ Intersubjetividad en Michel Henry: Relación Terapéutica
}

Maristela Vendramel Ferreira

Andrés Eduardo Aguirre Antúnez

\begin{abstract}
Resumo: A psicoterapia é realizada no contexto da relação terapêutica entre o psicoterapeuta e o paciente. A intersubjetividade se coloca como preponderante, pois é nesse registro que o trabalho terapêutico se desenvolve. Michel Henry (1922-2002), filósofo e romancista francês, desenvolveu a Fenomenologia da Vida, na qual é revelada o papel originário dos afetos na constituição do indivíduo, na sua relação consigo mesmo, com o outro e com o mundo. O objetivo deste trabalho é discutir a intersubjetividade dentro dos pressupostos teóricos da Fenomenologia da Vida de Michel Henry, tendo em vista o que este conhecimento contribui para a compreensão deste conceito relevante para a clínica psicológica.
\end{abstract}

Palavras-chave: Michel Henry; Intersubjetividade; Afetividade; Relação terapêutica.

\begin{abstract}
The psychotherapy develops in the context of the therapeutic relationship between the therapist and the patient. The intersubjectivity is fundamental because it is in this context that psychotherapeutic work is evolved. Michel Henry (1922-2002), French philosopher and novelist, developed the Phenomenology of Life, which reveals the originary role of affects in the individual's constitution in his relationship with himself, with others and with the world. The objective of this paper is to discuss intersubjectivity within the theoretical frame of the Michel Henry's Phenomenology of Life, considering what this knowledge contribute to the understanding of this relevant concept to the psychological clinic.
\end{abstract}

Keywords: Michel Henry; Intersubjectivity; Affectivity; Therapeutic relationship.

Resumen: La psicoterapia se realiza en el contexto de la relación terapéutica entre el terapeuta y el paciente. Se plantea la intersubjetividad como predominante, ya que en ella se desarrolla el trabajo terapéutico. Michel Henry (1922-2002), novelista y filósofo francés, desarrolló la Fenomenología de la Vida, en la cual se revela el papel originario de los afectos en la constitución de la persona y su relación con ellos mismos, con los demás y con el mundo. El objetivo de este trabajo es discutir la intersubjetividad dentro de los supuestos teóricos de la Fenomenología de la Vida de Michel Henry, teniendo en cuenta lo que este conocimiento contribuye en la comprensión de este concepto pertinente para la clínica psicológica.

Palabras-clave: Michel Henry; Intersubjetividad; Afecto; Relación terapéutica.

\section{Introdução}

A psicoterapia realiza-se no contexto da relação entre psicoterapeuta e paciente. A comunicação e o vínculo entre eles são fundamentais para que o processo ocorra e tenha êxito. Sousa (2006) aponta os fatores que mais contribuem para a promoção da mudança terapêutica, independentemente da orientação teórica do profissional. Dentre eles, dois aspectos apresentam-se como significativos. O primeiro relaciona-se ao próprio paciente, sua motivação para mudança, suas capacidades cognitivas e interpessoais e seu desejo de estabelecer um relacionamento com o psicoterapeuta. O segundo é a qualidade da relação terapêutica que é constituída pela dupla.

A questão da intersubjetividade, deste modo, torna-se essencial, pois é neste registro que o trabalho e as mudanças terapêuticas se realizam. A relação terapêutica, entretanto, se estabelece numa dinâmica além da psíquica, pois se refere à ontologia do homem, que é ori- ginariamente relacional. Safra (2006) discute que o ser humano é ontologicamente aberto ao outro, sendo esta abertura fundamental para sua constituição, pois o homem sempre acontece em comunidade. Esta acolhe o novo bebê que surge, provendo-o com os elementos necessários para que vá, com o tempo, se desenvolvendo e lidando com sua vida. Uma importante questão clínica que se coloca é como a família, a sociedade e, mais tarde, o psicoterapeuta, como ser humano posicionado em comunidade com seu paciente, acolhe e lhe oferece os recursos necessários para que lide com sua existência, que transcende o psiquismo.

Michel Henry (1990), em seu livro Phénoménologie Matérielle, tece os primeiros conceitos do que seria uma teoria da intersubjetividade - nunca concluída - e nos oferece subsídios para começarmos a elaborar a questão acima colocada. Ele trabalha o conceito da comunidade, que é estabelecida com o outro em pathos - definido como sendo a afetividade originária pura transcendental - ten- 
do como base o Fundo comum - que consiste na própria vida doada a todos nós. Essas concepções são essenciais para a compreensão da intersubjetividade e da dinâmica dos afetos que permeiam as relações terapêuticas na clínica psicológica.

Michel Henry (1963) teoriza que a possibilidade do conhecimento e da relação com o outro ocorre originariamente através da afetividade e pelo nosso nascimento comum como filhos da Vida. Desse modo, trata a questão da intersubjetividade de modo particular, situando-a como nossa condição ontológica de seres afetáveis e afetivos, nascidos na Vida.

Sua concepção de intersubjetividade fundada na afetividade é relevante para a clínica, pois o psicoterapeuta necessita compreender e se apropriar das vivências afetivas, como formas de comunicação e de estabelecimento do encontro ético humano na relação psicoterapêutica. Encontro que permite o desenvolvimento, tanto do paciente quanto do psicoterapeuta, e que preserva a vida.

Se nos detivermos exclusivamente no paradigma da representatividade - no qual a afetividade não é relevada e os atendimentos são conduzidos priorizando somente a racionalidade, as interpretações ou análise de comportamentos - certamente, não conseguiremos prover um ambiente vivo e humano que sustente o desenvolvimento emocional de nossos pacientes e que atenda às suas necessidades. Se isto suceder, poderemos oferecer uma ambiência e uma relação psicoterapêutica que reproduza o sofrimento e adoeça ainda mais o paciente, pois, ao invés de albergarmos a vida, estaremos degradando-a, dando contornos desumanos à nossa prática clínica.

O objetivo deste artigo, portanto, é discutir a noção de intersubjetividade na Fenomenologia da Vida de Michel Henry e o que esta poderia contribuir para ampliar o entendimento deste conceito deveras importante para a clínica.

\section{A Fenomenologia da Vida de Michel Henry}

Michel Henry (1922-2002) - filósofo e romancista francês - desenvolveu a original Fenomenologia da Vida, revelando o papel originário dos afetos na constituição do Si e na ligação deste com o mundo. Ele situa os fenômenos afetivos como centrais à compreensão do nosso ser e das nossas vivências (Martins \& Pereira, 2010).

Henry (2010) critica o pensamento ocidental e os efeitos da redução galileana, a partir da qual os aspectos subjetivos e a sensibilidade para conhecer o mundo foram colocados de lado e trocados pela geometria e pelo conhecimento racional, rigoroso e que enuncia propriedades universais ou científicas.

A redução galileana trouxe consequências metodológicas, onde para conhecer o universo material não se deve levar em conta as qualidades sensíveis nem as sensações, e consequências ontológicas, onde o ser humano fica reduzido a um corpo material. Neste caso é necessário compreendermos o alcance dessa redução, onde o que é subjetivo passa a ser considerado um mundo de aparências ilusórias, totalmente contingente e ligado a nossa condição de organismo vivo. De acordo com Wondracek (2010), a partir da redução galileana o que é considerado verdadeiro é somente o que pode ser representado e visto. Isto se mostra insuficiente para a compreensão da condição humana, pois esta é paradoxal na articulação entre a verdade visível e invisível.

Como afirma Henry (2010, p. 7) "A vida mantém-se por conseguinte sempre aquém do espetáculo, ela é literalmente invisível ainda que seja o que há de mais certo". Ater-se ao que é visto é ater-se à evidência, deixando de lado tudo o que não é evidente ou invisível. Ele relata que Descartes, contudo, desqualifica a própria evidência dizendo que o que posso ver com os sentidos ou com o espírito não tem credibilidade, mas que "at certe videre videor" significa "no mínimo, é muito certo que me parece que vejo". Podemos ser enganados a respeito das percepções fora de nós, mas não a respeito das paixões, pois é impossível que as sintamos sem que elas sejam verdadeiramente como as sentimos (Henry, 2008).

A experiência mais originária do ser humano é a afecção da Vida em cada Si. Todo ser humano possui um Si mesmo e se edifica como indivíduo na autodoação da Vida absoluta em si. Henry (1998) indica que a Vida absoluta, com V maiúsculo, é a que tem capacidade de criar a própria vida. A vida, então, se refere à nossa vida. A pessoa se descobre como Si mesma, como um Si real, e toma posse de si mesma se experimentando, provando-se, sentindo-se.

Henry assevera que o aparecer dos fenômenos é um auto-aparecer, onde a impressão é possível na afetividade transcendental do pathos "no qual toda vida e toda modalidade da vida vem a si, se abraça ela mesma nesse Si vivo" (Henry, 2001, p. 80). O pathos é definido como sendo a afetividade originária pura transcendental. Ela é denominada transcendental, pois por meio dela é possível a experiência de si no sofrer e no fruir das paixões. A auto-revelação da vida ocorre e manifesta-se nesta afetividade originária, no pathos, configurando-se este o modo fenomenológico do auto-aparecer que constitui a essência da vida. O pathos é o núcleo invisível da vida, fonte de irredutibilidade desta mesma vida, mas que ao mesmo tempo se desvela e se mostra como singularidade. Nesta relação de si consigo na vida, no pathos, no sofrer e no fruir, no padecer de si o Si constitui-se, desenvolve-se, encarnado.

Henry (2001) fundamenta este conceito de que a vida vem numa carne, num corpo subjetivo, na materialidade fenomenológica do pathos e sempre vem como vida de alguém, experimentada afetivamente em um si singular, numa carne singular, num eu particular. A existência e a realidade da vida são provadas na ipseidade do Si encarnado. 
Os fenômenos, por sua vez, se fenomenalizam no registro do duplo aparecer, sendo o visível o modo do mundo e o invisível o modo da vida. Nessa formulação Henry oferece um acréscimo fundamental à fenomenologia clássica proposta por Husserl, que enfatiza o aparecer visível dos fenômenos, o que se fenomenaliza à luz da consciência, na intencionalidade, na exterioridade do mundo ou na claridade e objetividade dos pensamentos (Henry, 1998). Realiza uma restauração fenomenológica da própria intencionalidade em sua origem não-intencional (Henry, 2006). Embora critique a fenomenologia clássica quando esta se fundamenta exclusivamente no aparecer do mundo (Henry, 2001), mantém-se alinhado a Husserl, não negando a importância da intencionalidade, mas propõe uma fenomenologia da vida mais originária, na não-intencionalidade e invisibilidade da afetividade.

Para contemplar os fenômenos na duplicidade de seu aparecer, visível e invisível, Henry realiza a inversão fenomenológica onde o que dá acesso à vida, geradora do homem e de todos os fenômenos, não é da ordem do pensamento. É a própria vida que permite ao pensamento aceder a si e se experienciar. Por conseguinte, a Fenomenologia da Vida redefine a racionalidade e situa o pensar, o cogito, declinado no corpo e no sentir, visto que a vida se dá como afeto num corpo dotado de sentidos. A inversão fenomenológica permite o acesso à vida, ao visível e ao invisível, e desta maneira possibilita gerar conhecimento e certificar os saberes incluindo o sentir (Martins, 2012).

\section{Intersubjetividade em Michel Henry}

Henry (1990) tece suas ideias iniciais sobre a questão da alteridade no livro Phénoménologie Matérielle. Contudo, anuncia para o futuro uma obra sobre intersubjetividade que, de fato, nunca se concretizou. Nesta obra introduz o conceito da comunidade patética ou pathos-com afirmando que

Aquilo pelo qual um Si é um Si, o modo pelo qual se preenche e acresce de si, é também o modo pelo qual vem originalmente nele tudo o que o pode afectar, nomeadamente o «ser» do outro. Ego e alter-ego têm um nascimento comum, uma mesma essência e é por ela que eles "comunicam": porquanto eles são vivos. Então, se a vida é uma afectividade transcendental que aufere em si a sua essência, o que haverá de estranho em, inevitavelmente, toda a intersubjectividade revestir a forma de uma comunidade pathética? (Henry, 2005, p. 13)

Assevera que o conhecimento do outro não se dá simplesmente por uma transposição perceptiva, por analogias, por semelhanças ou somente por funções do pensamento, mas pela partilha afetiva, em pathos-com. Nós vivemos, nos relacionamos e compreendemos o outro em pathos-com, paradigma da comunidade afetiva onde o laço e o conhecimento do outro se realizam primordialmente fora da representação. Para Henry, portanto a intersubjetividade só é possível na Vida, que é a mesma tanto para mim quanto para o outro.

Ressalta que ao abordarmos a intersubjetividade, nunca devemos partir de uma relação entre egos, mas de $\operatorname{Si}(\mathrm{s})$, pois

(...) todo o "ego" pressupõe nele um Si transcendental Vivo. Se todo o Si transcendental - O do outro assim como o meu - é gerado no processo de autogeração da Vida Absoluta, no Primeiro Si no qual ela se prova e frui a Si Mesma, então é o processo que é primeiro. Nele reside a possibilidade última, não apenas de cada Si vivo, mas do ser-com o outro, de todos os Si (s) - presentes, passados e futuros (Henry, 2002, p. 8).

Esta afirmação nos remete a um conceito central na Fenomenologia da Vida que é o Fundo comum. Formamos uma comunidade de vivos e compartilhamos o Fundo comum da Vidadoada a todos nós. Nascemos neste Fundo e ele não é diferente de nós, mas se manifesta, se identifica e se particulariza em cada um através da auto-afecção da vida em nós. Portanto, no Si sucede, simultaneamente, uma partilha coletiva da Vida e a sua revelação particular a cada um de nós. A experiência do outro já se inicia neste Fundo comum, nesta

(...) experiência primitiva, quase impensável, visto escapar a todo o pensamento, o vivo não é para si mais que o outro, ele é tão só uma pura prova sem sujeitos, sem horizonte, sem significação, sem objeto. O que ele prova é identicamente ele mesmo, o Fundo da vida, o outro enquanto ele é também esse Fundo - então ele prova o outro nesse Fundo e não nele mesmo, enquanto a própria prova que o outro faz do Fundo. Esta prova é outrem que tem o Fundo em si como o eu tem o Fundo nele. Mas isso nem o eu nem o outro representam. Por isso é o Mesmo no qual se abismam um e outro (Henry, 2005, p. 144-145).

A relação com o outro se estabelece nesse registro do Fundo comum, pois todos são igualmente doados na Vida e compartilham a mesma origem. Este tipo de comunicação primordial com a alteridade é irrepresentável, pois ocorre através da afetividade, essência da comunidade. Esta "é um lençol de água afectiva subterrânea, e cada um bebe aí a mesma água nessa fonte e nesse poço que é ele mesmo - mas sem o saber, sem se distinguir de si mesmo, nem do outro nem do Fundo" (Henry, 2005, p. 145).

$\mathrm{O}$ acesso direto ao outro pela afetividade, sem mediação, se dá através da passibilidade, que é a impossibilidade originária da pessoa se separar de si mesma, de sua vida, de seu sofrimento, de deixar de ser afetada. Nas palavras de Henry, passibilidade 
(...) é esta impossibilidade originária, de o ser vivo se separar da vida, que funda a sua própria incapacidade de se separar de si. Assim o ser vivo não pode separar-se a si mesmo do seu Si, da sua dor ou do seu sofrimento (Henry, 2001, p. 197).

Martins (2002) discute a fenomenologia da passividade do afeto e a questão da alteridade. Afirma que o outro é a Vida revelada como afetividade, como um Si particular, com suas possibilidades de ser e desfrutar de si. A alteridade é revelada a mim através da afetividade, da passibilidade e isto implica que temos uma sensibilidade, uma capacidade sensiente, que é o corpo, imanência subjetiva, que constitui a própria consciência e que é a "possibilidade de relação com o outro a partir de si" (Martins, 2002, p. 165). Enfatiza também que na capacidade sensiente não nos sentimos sós, pois

O seu devir afectivo constitui-nos verdadeiramente, faz-se nosso corpo e conjuntamente com a experiência deste é-nos dada a experiência do outro. A capacidade sensiente é doadora, faz-se dom em nós, destinatários desse dom. (Martins, 2002, p. 165)

Para a Florinda Martins na fenomenalidade do afeto provo muito mais do que eu mesma, pois o sentir é primordialmente relação. Provo-me em relação com a Vida em mim, com o mundo, com o outro. Portanto, dentro desta perspectiva da fenomenalidade do afeto, na relação não apenas provo a mim mesma como provo e conheço a alteridade (Martins, 2002).

Neste sentido, evidencia-se que somente as funções representativas, características da intencionalidade, não são suficientes para conhecer e estabelecer a relação com o outro, pois este aparece fora de qualquer intencionalidade. O outro, como eu, é dádiva da Vida, gerado como singularidade, como filho da Vida. Sendo assim o conhecimento e relação com o outro não ocorre primordialmente na intencionalidade, mas faz-se "pelo afeto, através da passibilidade e em co-pathos ou afetividade originária com o outro". (Martins, 2002, p. 156)

Rosendo (2012) relata que para Henry a solidão é um aspecto ôntico e não ontológico. Podemos sentir a experiência do outro não enquanto conteúdo, visto que é impossível sentir a dor do outro, mas

(...) percebo o ato formal e transcendental do seu sofrer e, por isso, emociono-me e comovo-me com as suas dores apesar de não serem concretamente as minhas. É, precisamente, por haver esta distância fenomenológica entre o Eu e o Outro que podemos percebê-lo como Outro (Rosendo, 2012, p. 7).

Henry (2012, p. 188) ressalta que “(...) os fenômenos de imitação e de "intropatia”, que estão no fundo da vida individual e social, se produzem no interior dessa esfera intersubjetiva afetiva que coloca em jogo as modalida- des patéticas das mônadas, que participam e se apoiam nelas". Deste modo, insere os conceitos de entropatia e imitação dentro do contexto mais amplo e originário da intersubjetividade afetiva, de pathos-com. Posiciona também a imitação como fenômeno diferente da entropatia. Embora diverso, o fenômeno da imitação, estudado pelo sociólogo Tarde, é apontado como um aspecto importante na constituição das relações intersubjetivas.

A intersubjetividade, assentada na partilha da Vida entre os vivos, em passibilidade, em comunidade pática, pré-representativa, é estabelecida inicialmente por imitação, onde a afecção da vida é ativada na presença do outro. Isto nos remete ao bebê na relação com sua mãe. Um bebê recém-nascido ainda não empatiza porque ainda não desenvolveu a capacidade de diferenciar o eu do não-eu. Ele partilha a mesma Vida que sua mãe, nasce em relação, em comunidade, em pathos-com. No processo de constituição de sua subjetividade - que permitirá em estágios posteriores o desenvolvimento da noção do outro, a entropataia, o pensamento, a linguagem, as representações - o laço afetivo e o cuidado dispensado na relação com sua mãe são fundamentais. Contudo, antes que fale, pense, represente ou empatize, o bebê já imita e já é afetado e contagiado por estados afetivos presentes em seu ambiente e na sua vida íntima.

Desse modo, poderíamos concluir que a possibilidade de conhecer o outro se inicia com a condição ontológica de sermos irmanados na Vida. Na passibilidade do sentir somos contagiados emocionalmente e imitamos. Com o desenvolvimento da subjetividade e da capacidade de representar podemos nos tornar empáticos.

As capacidades de reconhecer e compreender o outro ser humano podem ser discutidas dentro do registro do duplo aparecer, visível e invisível. Com Henry compreendemos que isto só é possível a partir de um a priori afetivo, não-intencional e pré-representativo. Posso desenvolver entropatia, posso representar e intencionar, pois já fui constituído e me desenvolvi a partir da auto-afecção da Vida em mim. A afetividade é fundadora da possibilidade da constituição e desenvolvimento de um Si que pode vir a ter entropatia, representar e intencionar.

A consciência do outro se configuraria impossível sem nossa constituição originária como sujeitos na afetividade. $\mathrm{O}$ aspecto representacional é um dos aspectos da fenomenalidade, que a seu modo gira em torno de um dado que pode ser tomado como modalidade objetal, como algo que vejo, e não a totalidade do fenômeno afetivo, que só pode ser alcançado por outro método. Henry contribui com a compreensão do aspecto não-intencional dessa representatividade, o afeto que funda a possibilidade do conhecimento e do laço afetivo com o outro. Este é o modo originário por meio do qual nos relacionamos com a alteridade e nos constituímos como sujeitos. A intersubjetividade, portanto, se estabelece no registro visível e invisível simultaneamente, no registro do duplo aparecer, fundada na afetividade e em registro de pathos. 
A noção de Henry se assenta em uma base afetiva e relacional da constituição do Si. O relacionamento mãe-bebê ocorre primordialmente no afeto, através do corpo e do cuidado, sendo no início eminentemente não representativo.

Ele considera a imitação é importante para a criação dos laços intersubjetivos. Contudo, não é somente através da imitação que se configura o conhecimento do outro. A imitação é relevante, mas é a afetividade, através da passibilidade, do fato de nascermos, crescermos e morrermos em pathos-com, que permitirá o conhecimento da alteridade.

\section{Considerações Finais}

A clínica deveria como todas as atividades humanas albergar a vida. Para tanto, não poderia distanciar-se das propriedades sensíveis e afetivas, pois isto consistiria num "afastamento da própria vida, isto é, do que constitui a humanidade do homem" (Henry, 2012, p. 43). Preservando a vida e o humano, a Fenomenologia da Vida contribui para a condução do trabalho clínico, a partir da afetividade, posicionada como essencial ao acontecer do homem (Antúnez \& Wondracek, 2012).

De acordo com Henry (2012, p. 188), “(...) a relação entre analista e analisando não passa de uma modalidade da intersubjetividade patética". Oferecendo-nos as bases ontológicas da intersubjetividade, sua fenomenologia nos fundamenta para compreendermos a relação terapêutica, leito no qual se desenrola a psicoterapia.

A partir dos conceitos de Henry acima expostos podemos afirmar que a relação terapêutica se estabelece no registro do Fundo comum, pois psicoterapeuta e paciente são igualmente nascidos na vida e compartilham a mesma origem. Já implicados e advindos do Fundo comum e em partilha afetiva, em pathos-com, psicoterapeuta e paciente, em passibilidade padecem juntos e se afetam mutuamente em uma tessitura de afetos na vida. O trabalho clínico, portanto, fica inscrito e é desenrolado na relação de passibilidade entre psicoterapeuta e paciente, cuja modalização dos afetos é um trabalho que estamos a desenvolver no projeto Internacional de investigação em Fenomenologia da Vida, em língua portuguesa: $O$ que pode um corpo?, coordenado cientificamente por Florinda Martins, a quem agradecemos.

\section{Referências}

Antúnez, A. E. A. \& Wondracek, K. H. K. (2012) Fenomenologia em Michel Henry: Implicações na Psicopatologia e Psicoterapia. Rev. Abordagem Gestalt, vol.18, n.1, p. 3-12.

Henry, M. (1963). L'essence de la manifestation. Paris: PUF.

Henry, M. (1990) Phénoménologie Matérielle. Paris: PUF.
Henry, M. (1998). Eu sou a verdade. Por uma filosofia do cristianismo. Tradução Florinda L. F. Martins. Lisboa: Vega.

Henry, M. (2001). Encarnação: por uma filosofia da carne. Tradução de Florinda L. F. Martins. Lisboa: Círculo de Leitores.

Henry, M. (2002) Prefácio. In Martins, F. Recuperar o Humanismo - Para Uma Fenomenologia da Alteridade em Michel Henry. (pp. 7-9). Principia: Cascais.

Henry, M. (2005). Fenomenologia Material. Maia, Portugal: Ed. Fomento.

Henry, M. (2006). Fenomenologia não-intencional (Textos Clássicos Lusosofia). Covilhã: Lusosofia Press.

Henry, M. (2008). O começo cartesiano e a ideia de fenomenologia (Textos Clássicos Lusosofia). Covilhã: Lusosofia: press.

Henry, M. (2010). As ciências e a ética (Textos Clássicos Lusosofia). Covilhã: Lusosofia: press.

Henry, M. (2012). A Barbárie. Tradução de Luiz Paulo Rouanet. São Paulo: É Realizações Editora.

Martins, F. (2002). Recuperar o Humanismo - Para Uma Fenomenologia da Alteridade em Michel Henry. Principia: Cascais.

Martins, F. (2012). Passibilidade e certificação dos saberes. Em F. Martins \& A. Pereira Poder é Saber. (pp. 29-47). Lisboa: Centro de Estudos de Filosofia da Universidade Católica Editora.

Martins, F. \& Pereira, A. (2010). Michel Henry: o que pode um corpo? Lisboa: Universidade Católica Editora.

Rosendo, A. P. (2012) Comunicação das consciências e contágio de sentimentos. Covilhã: Lusosofia: press.

Safra, G. (2006). Hermenêutica na Situação Clínica. O Desvelar da Singularidade pelo Idioma Pessoal. São Paulo: Sobornost.

Sousa, D. (2006). Investigação em psicoterapia: contexto, questões e controvérsias. Análise Psicológica, 3(XXIV), 373-382.

Wondracek, K. H. K. (2010). Ser nascido na vida: a fenomenologia da Vida de Michel Henry e sua contribuição para a clínica. Tese de Doutorado, Escola Superior de Teologia, São Leopoldo.

Maristela Vendramel Ferreira - Psicoterapeuta, Especialista em Psicoterapia Psicanalítica pelo Instituto de Psicologia da Universidade de São Paulo, Mestre em Distúrbios da Comunicação pela PUCSP, Doutora em Audiologia pela University of Southampton - Inglaterra - e Pós Doutoranda em Psicologia Clínica no Instituto de Psicologia da Universidade de São Paulo. Colaboradora científica do grupo de língua portuguesa no Fonds Michel Henry, Louvain-La-Neuve, Bélgica. E-mail: maristelavf@usp.com.br

Andrés Eduardo Aguirre Antúnez - Psicólogo, Mestre e Doutor pelo Departamento de Psiquiatria da Universidade Federal de São Paulo. Professor Livre-Docente do Departamento de Psicologia Clínica da Universidade de São Paulo.E-mail: antunez@usp.br 